\title{
Efficacy Assessment of Newly-designed Filtering Facemasks during the SARS-CoV-2 Pandemic
}

\section{Aerosol and Air Quality Research}

Special Issue:

Special Issue on COVID-19 Aerosol Drivers, Impacts and Mitigation (XI)

\section{OPEN ACCESS}

Received: July 21, 2020

Revised: November 3, 2020

Accepted: November 24, 2020

${ }^{*}$ Corresponding Author:

b.boogaard@erasmusmc.nl

\section{Publisher:}

Taiwan Association for Aerosol Research

ISSN: $1680-8584$ print ISSN: 2071-1409 online

Copyright: The Author(s). This is an open access article distributed under the terms of the Creative Commons Attribution License (CC BY 4.0), which permits unrestricted use, distribution, and reproduction in any medium, provided the original author and source are cited.

\section{Bob Boogaard ${ }^{1 *}$, Ali Tas ${ }^{4}$, Joep Nijssen ${ }^{2}$, Freek Broeren ${ }^{2}$, John van den Dobbelsteen ${ }^{2}$, Vincent Verhoeven ${ }^{3}$, Jip Pluim ${ }^{3}$, Sing Dekker ${ }^{3}$, Eric J. Snijder ${ }^{4}$, Martijn J. van Hemert ${ }^{4}$, Sander Herfst ${ }^{1}$}

${ }^{1}$ Department of Virology, Erasmus University Medical Center, 3015 GD Rotterdam, The Netherlands

2 Department of Precision and Microsystems Engineering, Department of Biomechanical Engineering, Delft University of Technology, 2628CN, Delft, The Netherlands

${ }^{3}$ Department of Medical Physics, Department of Infection Prevention, Reinier de Graaf Gasthuis, 2625 AD, Delft, The Netherlands

${ }^{4}$ Department of Medical Microbiology, Leiden University Medical Center, 2333 ZA, Leiden, The Netherlands

\section{ABSTRACT}

The SARS-CoV-2 pandemic resulted in shortages of production and test capacity of FFP2respirators. Such facemasks are required to be worn by healthcare professionals when performing aerosol-generating procedures on COVID-19 patients. In response to the high demand and short supply, we designed three models of facemasks that are suitable for local production. As these facemasks should meet the requirements of an FFP2-certified facemask, the newly-designed facemasks were tested on the filtration efficiency of the filter material, inward leakage, and breathing resistance with custom-made experimental setups. In these tests, the facemasks were benchmarked against a commercial FFP2 facemask. The filtration efficiency of the facemask's filter material was also tested with coronavirus-loaded aerosols under physiologically relevant conditions. This multidisciplinary effort resulted in the design and production of facemasks that meet the FFP2 requirements, and which can be produced at local production facilities.

Keywords: Coronavirus filtration efficiency, Facemask, FFP2, NaCl particle filtration, Respirator

\section{INTRODUCTION}

The severe acute respiratory syndrome coronavirus-2 (SARS-CoV-2) is a novel coronavirus that was first identified in December 2019 in Wuhan, China, in patients suffering from acute respiratory syndrome (2019 coronavirus disease or COVID-19) (Zhu et al., 2020). SARS-CoV-2 was declared pandemic by the WHO on March 11, 2020.

Healthcare professionals who are involved in aerosol-generating procedures on COVID-19 patients are required to use FFP2-classified filter facepiece respirators for respiratory protection against SARS-CoV-2 infection. FFP2-respirators (from now on called 'facemask') filter at least 94\% of the submicron-sized test aerosols with $\mathrm{NaCl}$, according to the NEN-EN 149:2001+A1:2009 standards (Table 1). These standards are used by the accredited test laboratories (the so-called notified bodies) within the European Union member states to test and certify the facemasks upon approval. According to these standards, FFP2-classified facemasks are also required to meet the criteria for inward leakage, maximal $\mathrm{CO}_{2}$-content of inhaled air, and breathing resistance, which are summarized in Table 1.

As the global demand for FFP2-facemasks largely exceeded the production, distribution and test capacities of the conventional suppliers and notified bodies during the COVID-19 pandemic, we formed a Dutch collaborative initiative, consisting of the Reinier de Graaf hospital, Royal DSM, 
Table 1. Requirements for FFP2-classified FFRs according to the NEN-EN149 standards.

\begin{tabular}{|c|c|c|c|c|}
\hline Filter penetration test & FIT-test & $\mathrm{CO}_{2}$ content test & \multicolumn{2}{|c|}{ Breathing resistance test } \\
\hline $\begin{array}{l}\text { Max. penetration of } \\
120 \mathrm{mg} \mathrm{NaCl} \text { test } \\
\text { aerosol at } 95 \mathrm{~L} \mathrm{~min}^{-1}\end{array}$ & Max. inward leakage & $\begin{array}{l}\text { Max. } \mathrm{CO}_{2} \text { content of } \\
\text { inhaled air }\end{array}$ & Inhalation & Exhalation \\
\hline $6 \%$ & $8^{a}$ or $11^{b} \%$ & $<1 \%$ on average & $\begin{array}{l}0.7 \mathrm{mbar} \text { at } 30 \mathrm{~L} \mathrm{~min}^{-1} \\
2.4 \mathrm{mbar} \text { at } 95 \mathrm{~L} \mathrm{~min}^{-1}\end{array}$ & $3.0 \mathrm{mbar}$ at $160 \mathrm{~L} \mathrm{~min}^{-1}$ \\
\hline
\end{tabular}

${ }^{a}$ for at least $8 / 10$ individual wearer arithmetic means.

${ }^{b}$ for at least 46/50 individual exercise results (e.g., 10 subjects $\times 5$ exercises).

Delft University of Technology, Leiden University Medical Center and Erasmus University Medical Center, with the aim to design facemasks that meet the FFP2-specifications. These facemasks were initially tested with custom-made test equipment on their filtration capacities of $\mathrm{NaCl}$ particles, fit, and breathing resistance under conditions that approximate the NEN-EN149 standards before being tested by a certified test laboratory. Those setups have been described in detail in Blad et al. (2020). The facemasks were also tested on virus filtration efficiency (VFE) with the mouse hepatitis virus (MHV), a beta coronavirus that causes lethal hepatitis in mice (Gledhill et al., 1955), but that is non-pathogenic to humans. These studies identified mask designs that filter $99 \%$ of coronavirus-loaded aerosols, just as a commercial FFP2-facemask.

\section{METHODS}

\subsection{Facemask Designs}

Three different types of in-house designed facemasks were tested in triplicate in various custom-made experimental setups. The "Reinier 0.1" facemask was constructed with a dental facemask, that consisted of two layers polypropylene nonwoven fabric ( 40 and $20 \mathrm{gr} \mathrm{m}^{-2}$ ) and a single layer of $20 \mathrm{~g} \mathrm{~m}^{-2}$ melt-blown fabric, to which two extra layers of spun-bond polypropylene filters (100 and $20 \mathrm{~g} \mathrm{~m}^{-2}$ ) was added. The "DSM 1.0" facemask consisted of five polypropylene nonwoven filter layers that consisted of $55 \mathrm{~g} \mathrm{~m}^{-2}$ spunmelt, $20 \mathrm{~g} \mathrm{~m}^{-2}$ melt-blown, $30 \mathrm{~g} \mathrm{~m}^{-2}$ meltblown, $20 \mathrm{~g} \mathrm{~m}^{-2}$ melt-blown, and $47 \mathrm{~g} \mathrm{~m}^{-2}$ spunmelt polypropylene filters. The name of this mask refers to the collaboration with the Dutch nutrition and health company Royal DSM during the development of this facemask. The "Reinier 1.0" facemask consisted of three layers of filter material, of which two layers of spun-bond polypropylene (100 and $20 \mathrm{gr} \mathrm{m}^{-2}$ ) and a single $20 \mathrm{gr} \mathrm{m}^{-2}$ melt-blown polypropylene layer. These facemasks were benchmarked against the FFP2-certified $3 \mathrm{M}$ Aura 1862(+) facemask. All layers of filter material were used throughout the masks and were therefore considered as homogeneously distributed. The electrostatic charge of the aerosols and material was not measured.

\subsection{The Dry Particle Penetration Test}

The dry environmental particle penetration test was performed to provide an initial indication of the filtering capacity of the in-house designed facemasks. The particles were counted by a Solair 3200 particle counter (Lighthouse), which is normally used for quality control measurements of the operating rooms. The particle counter was connected with a particle chamber, on which a facemask was fixed in an airtight manner. The particle counter generated a flow of $56.6 \mathrm{~L} \mathrm{~min}^{-1}$, which created an air velocity of $0.25 \mathrm{~m} \mathrm{~s}^{-1}$ through the facemask's filter material. Particles in the range of 0.3-0.5 $\mu \mathrm{m}, 0.5-1.0 \mu \mathrm{m}, 1.0-3.0 \mu \mathrm{m}, 3.0-5.0 \mu \mathrm{m}$, and 5.0-10.0 $\mu \mathrm{m}$ in size were counted. First, a reference count of the number of environmental particles (\# particles Ref) was performed in absence of a facemask and subsequently, the number of environmental particles was counted after fixing a facemask on the particle chamber (\# particles mask) and averaged over three oneminute measurements. For each of the five particle size ranges, the filter capacity was calculated according to the following formula:

Filter capacity $(\%)=\left(\left(\#\right.\right.$ particles $_{\text {Ref }}-\#$ particlesmask $) / \#$ particles Ref $) \times 100$ 


\subsection{NaCl Particle Penetration Test}

For the $\mathrm{NaCl}$ particle penetration test a PVC-tube system was constructed with a $90^{\circ}$ bend, going from a vertical to a horizontal direction (the design and instructions to build are online available at https://projectmask.nl/testing/filter-material-penetration/build/). The vertical part of the tube system was connected with an Atomizer Aerosol Generator ATM 226, and the distal end of the horizontal part contained a PMMA tube with a sample holder in which a facemask was fixed in an airtight manner (Figs. S1 and S2). The aerosol generator produced $\mathrm{NaCl}$ particles from a $2 \% \mathrm{NaCl}$ solution, resulting in a particle concentration of $2.5-3.5 \times 10^{4}$ particles $\mathrm{cm}^{-3}$ in the tube system. The number of $\mathrm{NaCl}$ particles that passed through the facemask's filter material was counted by a TSI PortaCount Pro 8030 particle counter, which detects particles in a 0.02 to $>1 \mu \mathrm{m}$ size range and generated an air velocity of $0.1 \mathrm{~m} \mathrm{~s}^{-1}$ through the filter material of the facemasks. The number of particles that passed through the filter material was analysed with TSI FitPro ${ }^{+}$software.

\subsection{The Fittest}

The fittest was performed to determine the leakage of particles around the edges of the facemasks. First, a probe was placed in the facemask by which it was connected to the PortaCount particle counter. To obtain representative results, each facemask was tested by three different individuals, who performed eight different exercises: normal breathing, deep breathing, moving the head side to side, moving the head up and down, talking, grimace, bending over and normal breathing, as described in the NEN-149 standards. The particle leakage was determined by comparing the number of particles in front and behind the facemask's filter material and was recorded with a PortaCount particle counter. The data were analysed with the TSI FitPro ${ }^{+}$software.

\subsection{The Breathing Resistance Test}

The breathing resistance of the facemasks was determined with a custom-made experimental setup (Fig. S3; the design and instructions to build are online available at https://projectmask.nl/ testing/breathing-resistance/build/). The facemask was placed on a manikin head (described in Zhuang and Bradtmiller, 2005) that was connected to a tube system, in which the pressure drop after the filter material was recorded. Before testing the facemasks, the pressure sensors were calibrated without any specimen at inlet or exit (open flow), blockage of the exit (blocked flow), or with a known flow resistance. When adding the masks, the increasing airspeed led to an increased airflow through the facemask and a pressure drop in the system, which was related to the resistance.

\subsection{Virus Filtration Efficiency Test}

As no standardized test procedures exist to determine the virus filtration efficiency of facemasks, an in-house designed experimental setup was developed that consisted of a curved tube with a $0.45 \mathrm{~m}$ vertical and a $0.9 \mathrm{~m}$ horizontal part with at the distal end a sample holder for airtight placement of a facemask (Fig. S4). This tube was connected to a mixing chamber, in which the virus-loaded aerosols were mixed with mist droplets of bidest, that was generated by a ultrasonic mist maker, for more efficient virus collection. The mixing chamber was connected to three SKC BioSampler impingers, in which the collected virus was impinged into $45 \mathrm{~mL}$ virus transport medium (VTM) (HMEM (Lonza), 12\% v/v glycerol, 0.5\% w/v Lactalbumin enzymatic hydrolysate, $0.02 \mathrm{mg} \mathrm{mL}^{-1}$ Polymyxin B sulfate, $0.01 \mathrm{mg} \mathrm{mL}^{-1}$ Nystatin, Penicillin/Streptomycin mixture $240 / 240 \mathrm{U} \mathrm{mL}^{-1}$ and $0.3 \mathrm{mg} \mathrm{mL}^{-1}$ ). The maximal airflow in each SKC BioSampler was $12.5 \mathrm{~L} \mathrm{~min}^{-1}$, generating a total maximal flow of $37.5 \mathrm{~L} \mathrm{~min}^{-1}$. The facemasks were challenged with mouse hepatitis virus (MHV), a beta coronavirus that causes hepatitis in mice, to be able to perform these tests under laboratory biosafety level (BSL) 2 conditions. $10^{8}$ plaque-forming units (PFUs) of MHV were aerosolized with an Aerogen Solo nebulizer, which produced small inhalable particles (MMAD $2.1 \mu \mathrm{m}$ ) in the vertical part of the tube. The particles were then directed through the $90^{\circ}$ bend, and subsequently the horizontal part of the tube system with the airtight fixed facemask. The facemasks were placed in the sample holder in an airtight manner between two sanitary rings with a diameter of $40 \mathrm{~mm}$, which created an air velocity of $0.42 \mathrm{~m} \mathrm{~s}^{-1}$ at a continuous airflow of $31.5 \mathrm{~L} \mathrm{~min}^{-1}\left(3 \times 12.5 \mathrm{~L} \mathrm{~min}^{-1}\right.$ minus $6 \mathrm{~L} \mathrm{~min}^{-1}$ for the mist maker $)$. The selfmade facemasks were tested in triplicate and benchmarked against the FFP2-certified 3M Aura 
1862(+) facemask. The aerosolized virus was also collected in the absence of a facemask as a reference. Between each test, the tube system was flushed with HEPA-filtered air for 15 min at a flow of $37.5 \mathrm{~L} \mathrm{~min}^{-1}$.

\subsection{Virus Quantification}

Viral RNA copy number was quantified by a quantitative reverse-transcription polymerase chain reaction (RT-qPCR) analyses and the number of infectious virus particles by plaque assays.

For RT-qPCR, viral RNA was isolated from $135 \mu$ I VTM with the QIAamp Viral RNA Mini Kit (Qiagen) according to the manufacturer's protocol. Equine arteritis virus (EAV) was added to the lysis buffer as an internal control for the RNA isolation and RT-qPCR efficiency as described in Scheltinga et al. (2005). The isolated RNA was converted to copy DNA (cDNA) and quantified in a TaqMan Fast Virus 1-step master mix (Applied Biosystems) in the presence of $450 \mathrm{nM}$ primers (MHV-FPr1: ACGCCGCCTTATTAAAGATG, MHV-RPr1: GGCATAGCACGATCACATTT) and $200 \mathrm{nM}$ probe (TexRed-TCCTGTACTCATGGGTT GGGACTATCC-BHQ2) that targets the viral gene nsp12, coding for RNA dependent RNA polymerase (RdRp). The primers and probe for the EAV internal control were also added and have been described in Loens et al. (2012). The reactions were run in a CFX384 Q-PCR Thermocycler (BioRad) with a two-step protocol: Cycle $1(1 \times)$ : $50^{\circ} \mathrm{C}, 5 \mathrm{~min}$. and $95^{\circ} \mathrm{C}$ for $20 \mathrm{sec}$., and Cycle $2(45 \times)$ : $95^{\circ} \mathrm{C}$ for $5 \mathrm{sec}$. and $60^{\circ} \mathrm{C}$ for $30 \mathrm{sec}$. An MHV standard was generated by in vitro transcription with the T7 mMessage mMachine kit (ThermoFisher) according to the manufacturer's protocol and was also analysed as described above to determine the copy number of viral RNA in the samples.

The number of infectious virus particles was determined by a plaque assay. $8 \times 10^{5} 17 \mathrm{CL} 1$ cells, derived from mouse (Mus musculus) BALB/c fibroblasts, were seeded in six-wells plates and incubated overnight at $37^{\circ} \mathrm{C}$. The cells were inoculated with an undiluted or one of the diluted MHV samples from a ten-fold serial dilution for $1 \mathrm{hr}$ at $37^{\circ} \mathrm{C}$. After inoculation, the cells were washed twice with PBS, overlaid with an Avicell (Sigma) overlay, and incubated for an additional $24 \mathrm{hrs}$ at $37^{\circ} \mathrm{C}$. The cells were subsequently fixated with $3.4 \%$ formaldehyde in PBS for $1 \mathrm{hr}$ at room temperature and stained with $0.75 \%$ crystal violet staining solution for 5 min at room temperature. After removal of the staining solution, the wells were washed with water, and the number of plaques was counted.

\section{RESULTS AND DISCUSSION}

\subsection{NaCl Particles were more Efficiently Filtered than the Environmental Particles of between $0.3-0.5 \mu \mathrm{m}$}

The filtering capacities of the new facemasks were initially determined by measuring the filtration of dry environmental particles in a broad particle size range $(0.3-10 \mu \mathrm{m})$ with a Solair 3200 particle counter by airtight placement of one of the facemasks on the particle chamber. A technical limitation of using the Solair 3200 particle counter is that only particles larger than $0.3 \mu \mathrm{m}$ were counted. The broad particle size range was chosen to obtain a general impression on the filtering capacities of the new facemasks. Furthermore, it is currently unknown what particle sizes are relevant for the airborne transmission of the SARS-CoV-2. The size of the virus particle is estimated to be $0.1 \mu \mathrm{m}$, but to which extend transmission takes places via aerosols ( $<5 \mu \mathrm{m}$ droplets) or larger respiratory droplets $(>5 \mu \mathrm{m})$ remains to be determined. When the FFP2-certified facemask was placed on the particle chamber, 99.4-99.9\% of the environmental particles of between 0.3-10.0 $\mu \mathrm{m}$ was filtered (Fig. 1(a)). Two models of the self-designed masks showed significantly lower filtration efficiencies for particles of between $0.3-0.5 \mu \mathrm{m}$ than the certified mask, in which the Reinier 0.1 filtered $74.6 \pm 0.4 \%$ and the Reinier $1.088 .2 \pm 0.8 \%$. The DSM 1.0 performed better than the other two models in this size range as this mask filtered 97.9 $\pm 0.3 \%$ of these particles. At least $96.9 \%$ of the particles larger than $0.5 \mu \mathrm{m}$ were filtered by each of the three models. These observations indicate that the various types of masks are able to filter a significant amount of environmental particles. However, as the most penetrating particle size (MPPS) for fibrous filters has been shown in literature to vary between 0.03-0.5 $\mu \mathrm{m}$ (Lee and Liu, 1980; Podgorski et al., 2006; Rengasamy et al., 2009), further testing with submicron-sized $\mathrm{NaCl}$ particles under standardized conditions is required. 
(a)

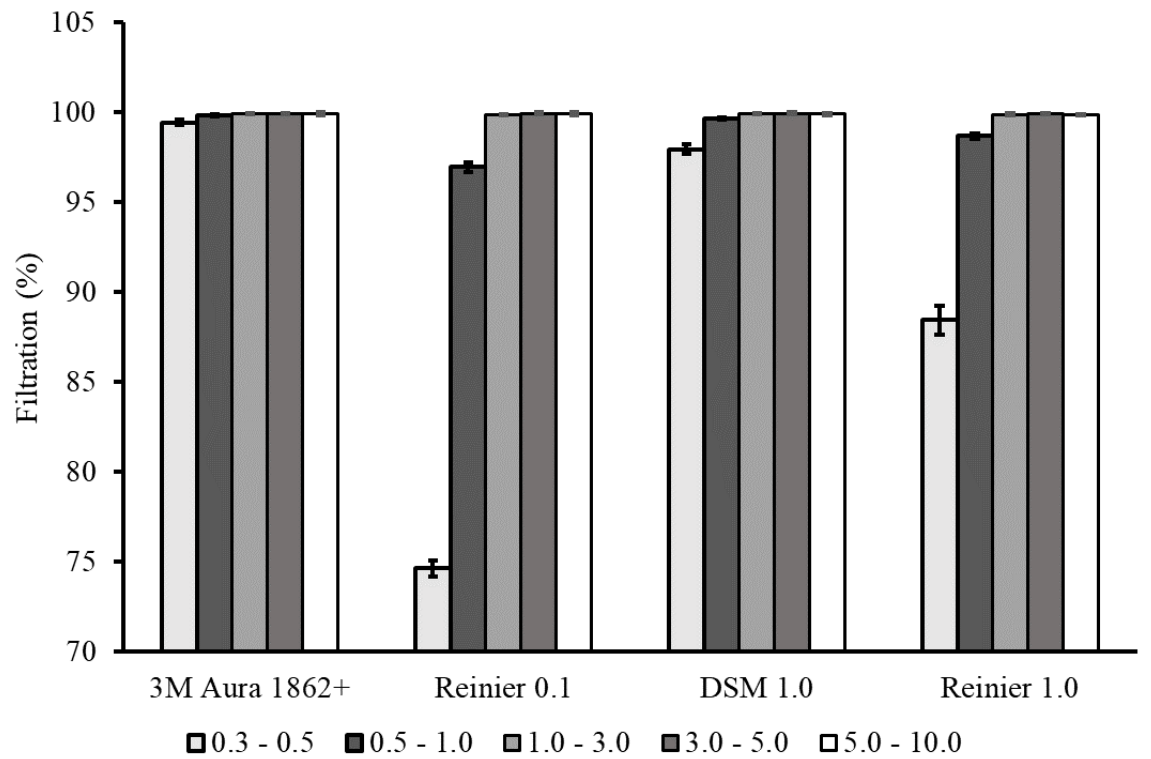

(b)

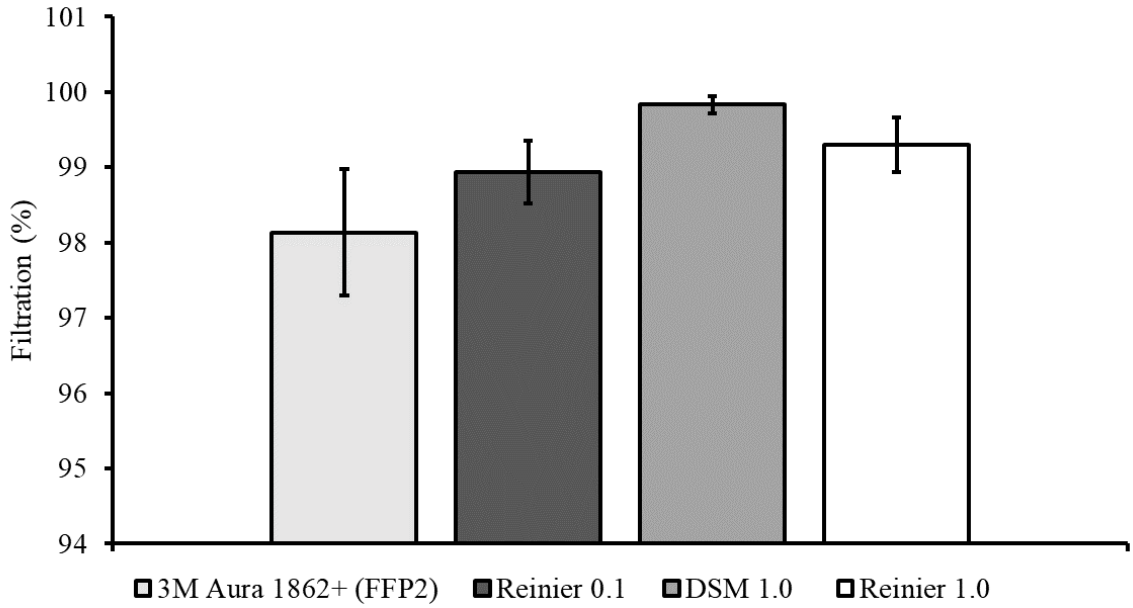

Fig. 1. (a) Filtration efficiency (mean $\pm \mathrm{sd}$.) of environmental dry particles and (b) non-neutralized polydisperse $\mathrm{NaCl}$ particles by the manually-produced facemasks and benchmarked against an FFP2-certified facemask.

The masks were therefore also challenged with non-neutralized polydisperse $\mathrm{NaCl}$-particles (0.02-2.0 $\mu \mathrm{m}$; MMD: $0.6 \mu \mathrm{m}$ ) under conditions that closely approximate the NEN-149 standards. According to these standards, FFP2-facemasks are required to filter at least $94 \%$ of the $\mathrm{NaCl}$ particles. The FFP2-certified facemask filtered $98.13 \pm 0.84 \%$ of the $\mathrm{NaCl}$ particles (Fig. 1(b)). The Reinier-0.1 and -1.0 facemasks filtered respectively $98.9 \pm 0.42 \%$ and $99.3 \pm 0.36 \%$ of the $\mathrm{NaCl}$ particles. This is significantly more than observed for the dry environmental particles of between $0.3-0.5 \mu \mathrm{m}$. These two models contained a single layer of melt-blown polypropylene and the above-described observations indicate that the two layers nonwoven fabric of the three-layer dental facemask of the Reinier-0.1 model can be removed without affecting the facemask's filtering performance. The DSM 1.0-facemasks is the only type with three layers of melt-blown polypropylene filters and showed the highest $\mathrm{NaCl}$-particle filtration efficiency of $99.83 \pm 0.12 \%$ (Fig. 1(b)). This model also performed best in the environmental particle filtration test (Fig. 1(a)).

The submicron-sized environmental particles were filtered less efficiently by the newlydesigned facemasks than the $\mathrm{NaCl}$ particles, which might be explained by the higher air velocity during the environmental particle filtration test. It has been well described in literature that an higher air velocity results in a lower filtration efficiency (Rengasamy et al., 2010, 2011, Miguel, 2013, Gao et al., 2016, Mukhametzanov et al., 2016). Another explanation is that the MPPS of the Reinier-0.1 and -1.0 mask coincidently fell between $0.3-0.5 \mu \mathrm{m}$ during the environmental 
particle filtration test, while under the standard conditions with $\mathrm{NaCl}$ particles the MPPS might be an order of magnitude smaller as previously observed by Rengasamy et al. (2009), since the MPPS is dependent on aerosol type (He et al., 2013) and air velocity (Lee and Liu, 1980). Furthermore, it has been shown by others that particles of other sources might have higher penetration rates than the $\mathrm{NaCl}$-particles (Penconek et al., 2013; Grima-Olmedo et al., 2014, Serfozo et al., 2017). Although the $\mathrm{NaCl}$ particle filtration test might overestimate a mask's filtering performance, this test is currently the golden standard when assessing the facemask's filter capacity. The NaCl-particle filtration efficiency of the Reinier 0.1- and DSM 1.0-facemasks was also verified by notified bodies and showed similar filtration efficiencies as in this study (Figs. S5 and S6), confirming that the custom-made setup indeed results in similar observations as under the conditions of the NEN149 standards. Hence, a good indication has been obtained that the filter capacity of the three types of facemasks meets the FFP2 requirement under standardized conditions.

\subsection{Reinier-0.1 and -1.0 Facemasks have Acceptable Inward Leakage and Breathing Resistance}

A proper fit and acceptable breathing-resistance are also crucial for the protective quality of a facemask. FFP2-certified facemasks are allowed to have an average inward leakage of maximal 8 or $11 \%$, depending on the number of tests and exercises, according to the NEN-149 standards. (Table 1). As our facemasks were tested by only three different persons, not the average, but maximal observed inwards leakage was taken as a measure for the fit of a facemask (Table 2), thus defining a worst-case scenario. The FFP2-certified facemasks showed a maximal inward leakage of $0.5 \%$ (Table 2). Of the self-designed masks, the Reinier-0.1 and -1.0 models have acceptable fits of below $8 \%$, whereas the DSM 1.0 shown significant leakage of $14.6 \%$. For the breathing resistance tests, the facemasks were placed on a manikin head and the pressure drop was recorded while the airflow was increased. The maximal pressure drop at an inhalation flow of 30 or $95 \mathrm{~L} \mathrm{~min}-1$ according to the NEN-149 standards is 0.7 and 2.4 mbar respectively. The pressure drops varied between 0.14 and $0.16 \mathrm{mbar}$ at a continuous flow of $30 \mathrm{~L} \mathrm{~min}^{-1}$, and at a flow of $95 \mathrm{~L} \mathrm{~min}^{-1}$, the pressure drop varied between 0.74 and 0.85 mbar for all three facemask models (Table 3). Exhalation at a continuous flow of $160 \mathrm{~L} \mathrm{~min}^{-1}$ resulted in a pressure drop of between 1.11 and 1.44 mbar for the three different designs, which is below the 3.0 mbar that is allowed according to the NEN-149 standards. These observations indicate that all three designs meet the NEN149 standards regarding breathing resistance. However, for the DSM-facemask this result might be due to the significant amount of inward leakage.

\subsection{The Prototype Facemasks Filter at Least $98 \%$ of Virus-loaded Aerosols}

The facemask were also challenged with virus-loaded aerosols as an extra testcase for the filtration capacities of the new facemasks in addition to the conventional test with $\mathrm{NaCl}$ particles.

Table 2. Maximal and minimal observed inward leakage.

\begin{tabular}{lll}
\hline Facemask & Max. observed inward leakage (\%) & Min. observed inward leakage (\%) \\
\hline 3M Aura 1862+ (FFP2) & 0.5 & 0.5 \\
Reinier 0.1 & 4.8 & 4.2 \\
DSM 1.0 & 14.6 & 6.7 \\
Reinier 1.0 & 0.8 & 0.5 \\
\hline
\end{tabular}

Table 3. Pressure drop over the self-designed facemasks at continuous inhalation flows of 30 or $95 \mathrm{~L} \mathrm{~min} \mathrm{~m}^{-1}$ and an exhalation flow of $160 \mathrm{~L} \mathrm{~min}^{-1}$.

\begin{tabular}{llll}
\hline Facemask & $\begin{array}{l}\text { Inhalation } 30 \mathrm{~L} \mathrm{~min}^{-1} \\
(0.7 \text { mbar max. })\end{array}$ & $\begin{array}{l}\text { Inhalation } 95 \mathrm{~L} \mathrm{~min}^{-1} \\
(2.4 \text { mbar max. })\end{array}$ & $\begin{array}{l}\text { Exhalation } 160 \mathrm{~L} \mathrm{~min} \\
(3.0 \text { mbar max. })\end{array}$ \\
\hline Reinier 0.1 & $0.14 \pm 0.003$ & $0.74 \pm 0.009$ & $1.44 \pm 0.05$ \\
DSM 1.0 & $0.14 \pm 0.003$ & $0.84 \pm 0.008$ & $1.31 \pm 0.06$ \\
Reinier 1.0 & $0.16 \pm 0.002$ & $0.85 \pm 0.01$ & $1.11 \pm 0.06$ \\
\hline
\end{tabular}


Furthermore, this test was strongly demanded by the healthcare professionals. $10^{8} \mathrm{PFU}$ of MHV, a beta coronavirus that infects mice, was aerosolized in our custom-designed tube system and passed through the filter material of each airtight fixated mask. The high number of PFU was required to observe at least 2 logs decrease in the number of PFUs, equivalent to 99\% filtration, as it was expected that most virus particles might be lost after aerosolization into the tube system. This number of virus particles is orders of magnitude larger than the number of infectious SARS-CoV-2 particles that was sampled in a patient room with two COVID-19 patients (Lednicky et al., 2020). The virus was aerosolized with an Aeroneb Solo nebulizer, which creates small inhalable particles (MMAD $2.1 \mu \mathrm{m}$ ). When those particles were passed through a tube over $0.9 \mathrm{~m}$ distance, $99 \%$ of the particles were $<5.0 \mu \mathrm{m}$ in size (Fig. 2). Particles smaller than $5.0 \mu \mathrm{m}$ are generally defined as aerosols that can be easily inhaled (Heyder et al., 1980). The three types of facemask were tested in two separate sessions, which resulted in two independent datasets (Fig. 3) In the no mask-control, MHV was sampled in absence of a facemask in the sample holder to determine the maximum amount of virus that could be recovered from the air. This resulted in virus recovery of $4.09 \pm 0.21 \mathrm{log}$ PFU mL $\mathrm{m}^{-1}$ in the first, and $5.89 \pm 0.21 \mathrm{log} \mathrm{PFU} \mathrm{mL} \mathrm{m}^{-1}$ in the second session (Figs. 3(a) and 3(c)), indicating that the virus collection efficiency in the latter session was higher than in the first session. Nevertheless, the collection efficiency of infectious virus particles was high enough to observe at least a 2-logs decrease in virus collection after placing a facemask in the sample holder. When an FFP2-certified facemask was placed in the sample holder, the amount of infectious virus and viral RNA copies that were recovered behind the facemask were respectively on average 2.3- and 2.4-logs lower than in the no-mask control in the first session. This corresponds to filtration efficiencies of 99.4 and $99.6 \%$ (Fig. 3(b)). When this type of facemask was used in the second session, the infectious virus and viral RNA recovery decreased by respectively 3.1- and 3.5-logs on average, which corresponds to 99.92 and $99.96 \%$ filtration efficiency (Fig. 3(d)). The Reinier-0.1 facemasks reduced the recovery rates of infectious virus and RNA copies on average by 2.1 and 2.8-logs respectively compared to the no maskcontrol (Fig. 3(a)). This corresponds with the filtration efficiencies of 99.2 and $99.9 \%$ (Fig. 3(b)). 2.3 and 2.6 - $\log$ reductions were observed with the DSM 1.0-facemasks, which corresponds with 99.3 and $99.6 \%$ filtration efficiency. The Reinier-1.0 facemasks were tested in the second session, which reduced the infectious virus and total viral RNA copy numbers with 3.1- and 2.6 logs on average, corresponding to 99.92 and $99.71 \%$ filter efficiency (Figs. 3(c) and 3(d)). The RNA copy $\mathrm{nr}$ to PFU-ratio with and without facemask are similar within each experiment, indicating that the mask's filter material does not inactivate the virus upon passage.

The virus filtration efficiency of the facemasks was determined at a continuous air velocity of $0.42 \mathrm{~m} \mathrm{~s}^{-1}$, which is significantly higher than during the $\mathrm{NaCl}$ particle penetration test, that was performed under conditions according to the NEN-149 standard. Similar filtration efficiencies

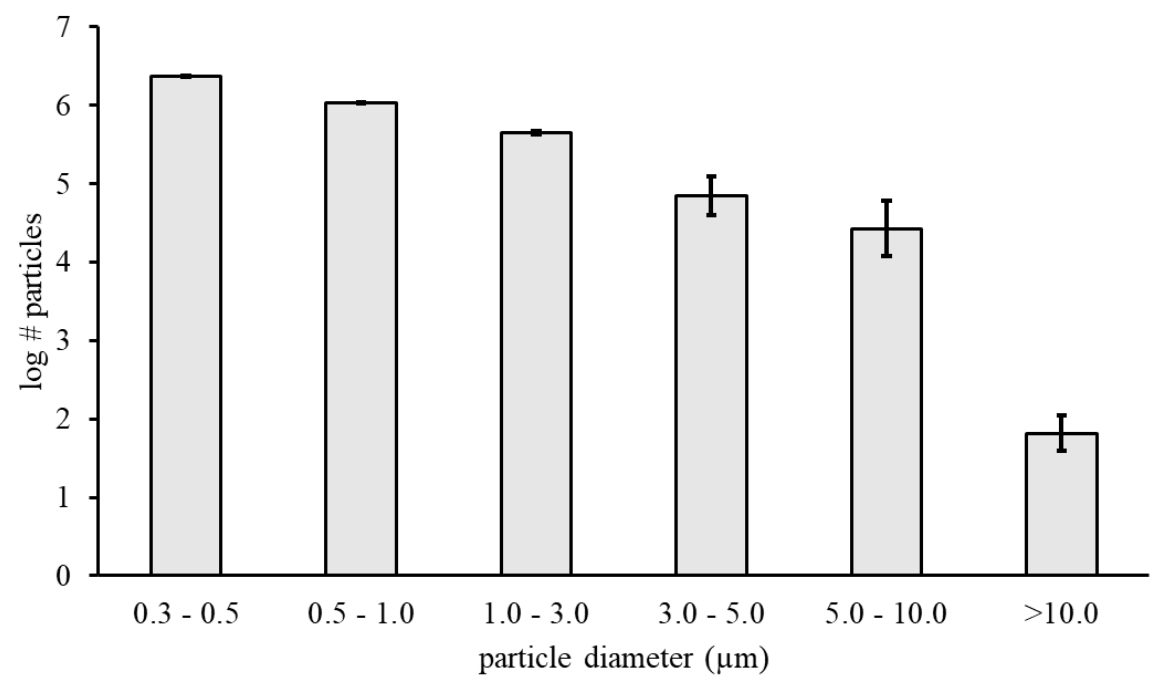

Fig. 2. Particle size range distribution (mean $\pm \mathrm{sd}$.) after aerosolization of $100 \mu \mathrm{L}$ virus diluent by the Aeroneb Solo nebulizer and passage through a $0.9 \mathrm{~m}$ tube. 


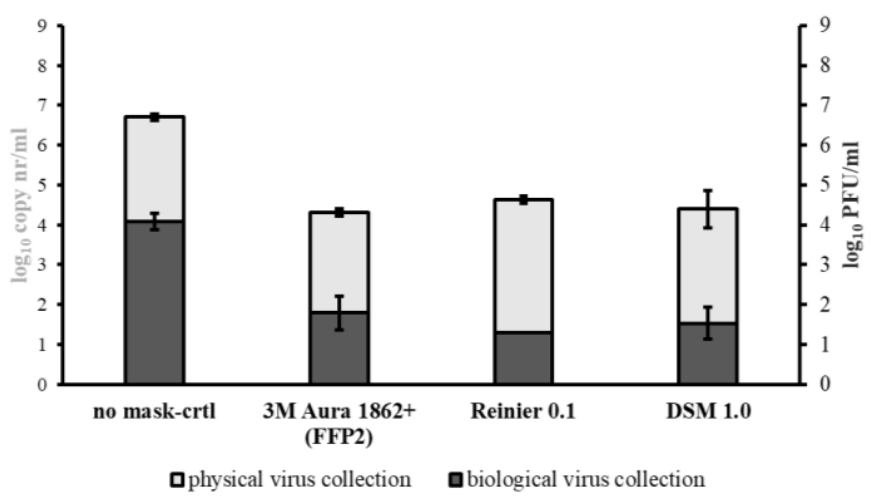

(a)

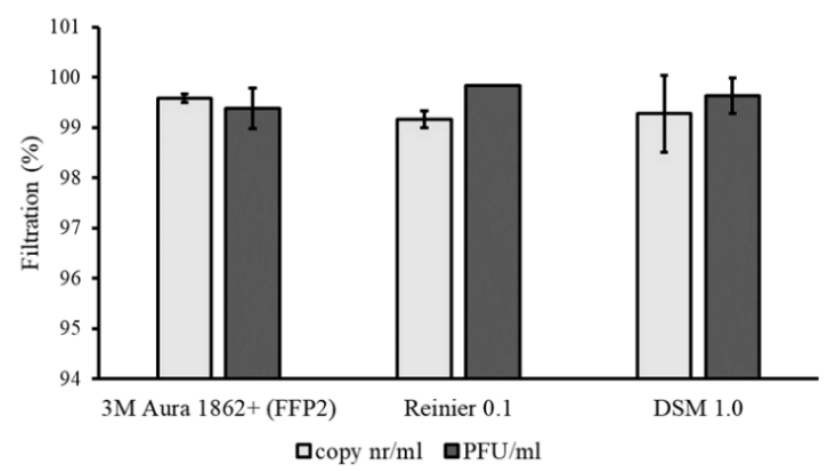

(b)

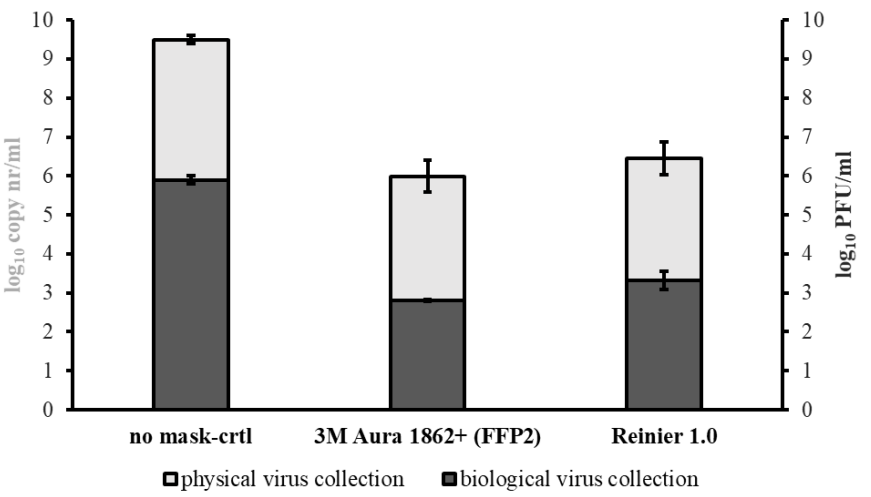

(c)

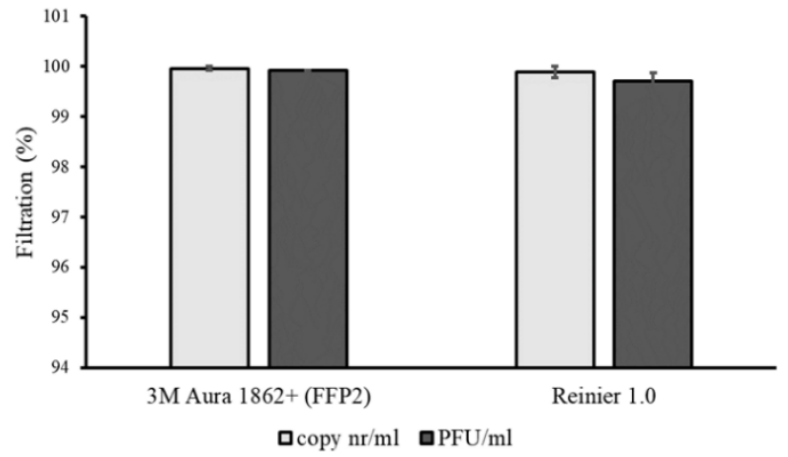

(d)

Fig. 3. Physical (copy $\mathrm{nr} \mathrm{mL}^{-1}$ ) and biological (PFU mL $\mathrm{m}^{-1}$ ) collection of (a and $\mathrm{c}$ ) aerosolized mouse hepatitis virus and (b and d) filtration efficiencies for the self-designed facemasks. The FFP2-certified mask was used as a benchmark.

were nevertheless observed as in the $\mathrm{NaCl}$ particle filtration test, which might be explained by larger sizes of the virus-loaded aerosols compared to the $\mathrm{NaCl}$ particles. The penetration rates of specifically the submicron-sized virus-loaded aerosols could unfortunately not be determined in this experiment. The biological origin of the virus-loaded aerosols is not relevant for the filtration efficiency by a facemask (Rengasamy et al., 2017). The air velocity used in present study was also higher than described in various other studies where the virus filtration efficiencies of facemasks were tested (Borkow et al., 2010; Harnish et al., 2013, 2016; Rengasamy et al., 2017; Zhou et al., 2018). It was chosen here to test at $0.42 \mathrm{~m} \mathrm{~s}^{-1}$ as this is a more physiological relevant air velocity during inhalation as the maximal air velocity during an inhalation cycle reaches up to $1 \mathrm{~m} \mathrm{~s}^{-1}$ (Tang et al., 2013). Despite the higher air velocity and the usage of a different virus, at least $98 \%$ of the virus-loaded aerosols were filtered by the FFP2-certified facemask, similarly as observed in the prementioned studies. However, significant lower virus filtration efficiencies ( $79 \%$ on average) were observed in a recently published airborne simulation experiment at an air velocity of $2 \mathrm{~m} \mathrm{~s}^{-1}$ (simulating coughs) when testing airtight fixated $\mathrm{N} 95$ facemasks on a recipient mannikin head (Ueki et al., 2020). The virus-loaded aerosols can apparently be forced through the filter material at this air velocity, which severely affected the filtering efficiency a facemask. Furthermore, when the N95-mask was not airtightly fixed to the mannikin-head, which would be the case in practice, the virus filtration efficiency was found comparable with that of a surgical mask. So although our self-designed masks were shown here to filter submicron-sized $\mathrm{NaCl}$ particles and virus-loaded aerosols, and showed acceptable breathing resistance and fits, more research under realistic conditions is needed to assess the protective capacity of the new facemasks.

\section{CONCLUSION}

It is concluded that under standardized conditions the Reinier-0.1 and -1.0 facemasks meet 
the requirements of the NEN-149 standards in terms of filtration capacity, breathing resistance and fit. The self-designed masks were also shown to filter $99 \%$ of virus-loaded aerosols after airtight fixation, but more research is needed to assess the protective capacity of these masks.

\section{ACKNOWLEDGMENTS}

This work was supported by the NIH/NIAID (contract number HHSN272201400008C) and European Union's Horizon 2020 research and innovation program VetBioNet (grant agreement No 731014). Part of this research was supported by the Leiden University Fund (LUF), the Bontius Foundation, and donations from the crowdfunding initiative "wake up to corona". S.H. was funded in part by an NWO VIDI grant (contact number 91715372). Part of this research was supported by ZonMw initiative "creative solutions against CoVID-19" (5001-0013). The authors also wish to thank Monique Elsing-van Olphen for supporting this research and for supplying information on the facemask designs.

\section{SUPPLEMENTARY MATERIAL}

Supplementary data associated with this article can be found in the online version at https://doi.org/10.4209/aaqr.2020.07.0424

\section{REFERENCES}

Blad, T., Nijssen, J., Broeren, F., Boogaard, B., Lampaert, S., van den Toorn, S., van den Dobbelsteen, J. (2020). A Rapidly Deployable test suite for respiratory protective devices in the COVID-19 pandemic. Appl. Biosaf. 25, 161-168. https://doi.org/10.1177/1535676020947284

Borkow, G., Zhou, S. S., Page, T., Gabbay, J. (2010). A novel anti-influenza copper oxide containing respiratory face mask. PLoS One, 5, e11295. https://doi.org/10.1371/journal.pone.0011295

Gao, S., Kim, J., Yermakov, M., Elmashae, Y., He, X., Reponen, T., Grinshpun, S.A. (2016). Performance of N95 FFRs against combustion and $\mathrm{NaCl}$ aerosols in dry and moderately humid air: Manikin-based study. Ann. Occup. Hyg. 60, 748-760. https://doi.org/10.1093/annhyg/me w019

Gledhill, A.W., Dick, G.W.A., Niven, J.S. (1955). Mouse hepatitis virus and its pathogenic action. J. Pathol. Bacteriol. 69, 299-309. https://doi.org/10.1002/path.1700690138

Grima-Olmedo, C., Ramírez-Gómez, Á., Medic-Pejic, L., García-Torrent, J. (2014). The penetration of respiratory protective devices by respirable solid particles. J Aerosol Sci. 74, 36-41. https://doi.org/10.1016/j.jaerosci.2014.03.008

Harnish, D.A., Heimbuch, B.K., Husband, M., Lumley, A.E., Kinney, K., Shaffer, R.E., Wander, J.D. (2013). Challenge of N95 filtering facepiece respirators with viable H1N1 influenza aerosols. Infect. Control Hosp. Epidemiol. 34, 494-499. https://doi.org/10.1086/670225

He, X., Grinshpun, S A., Reponen, T., Yermakov, M., McKay, R., Haruta, H., Kimura, K. (2013). Laboratory evaluation of the particle size effect on the performance of an elastomeric halfmask respirator against ultrafine combustion particles. Ann. Occup. Hyg. 57, 884-897. https://doi.org/10.1093/annhyg/met014

Heyder, J., Gebhart, J., Stahlhofen, W. (1980). Inhalation of aerosols: Particle deposition and retention. Generation of aerosols and facilities for exposure experiments, pp. 65-103.

Lednicky, J.A., Lauzardo, M., Fan, Z.H., Jutla, A., Tilly, T.B., Gangwar, M., Usmani, M., Shankar, S.N., Mohamed, K., Eiguren-Fernandez, A., Stephenson, C.J., Alam, M.M., Elbadry, M.A., Loeb, J.C., Subramaniam, K., Waltzek, T.B., Cherabuddi, K., Morris, J.G., Wu, C.Y. (2020). Viable SARS CoV-2 in the air of a hospital room with COVID-19 patients. Int. J. Infect. Dis. 100, 476-482. https://doi.org/10.1016/j.ijid.2020.09.025

Lee, K.W., Liu, B.Y.H. (1980). On the minimum efficiency and the most penetrating particle size for fibrous filters. J. Air Pollut. Control Assoc. 30, 377-381. https://doi.org/10.1080/00022470. 1980.10464592

Loens, K., Van Loon, A.M., Coenjaerts, F., Van Aarle, Y., Goossens, H., Wallace, P., Leven, M 
(2012). Performance of different mono-and multiplex nucleic acid amplification tests on a multipathogen external quality assessment panel. J. Clin. Microbiol. 50, 977-987. https://doi.org/10.1128/JCM.00200-11

Miguel, A.F. (2003). Effect of air humidity on the evolution of permeability and performance of a fibrous filter during loading with hygroscopic and non-hygroscopic particles. J. Aerosol Sci. 34, 783-799. https://doi.org/10.1016/S0021-8502(03)00027-2

Mukhametzanov, I.T., Grinshpun, S.A., Zaripov, S.K., Gilfanov, A.K. (2016). Assessing the protection provided by facepiece filtering respirator: New model involving spherical porous layer with annular peripheral opening. Aerosol Air Qual. Res. 16, 2428-2437. https://doi.org/ 10.4209/aaqr.2015.07.0466

NEN-EN 149:2001+A1:2009. Respiratory protective devices -Filtering half masks to protect against particles - Requirements, testing, marking. 2009

Penconek, A., Drążyk, P., Moskal, A. (2013). Penetration of diesel exhaust particles through commercially available dust half masks. Ann. Occup. Hyg. 57, 360-373. https://doi.org/10.109 3/annhyg/mes074

Podgorski, A., Bałazy, A., Gradoń, L. (2006). Application of nanofibers to improve the filtration efficiency of the most penetrating aerosol particles in fibrous filters. Chem. Eng. Sci. 61, 68046815. https://doi.org/10.1016/j.ces.2006.07.022

Rengasamy, S., Eimer, B.C., Shaffer, R.E. (2009). Comparison of nanoparticle filtration performance of $\mathrm{NIOSH}$-approved and $\mathrm{CE}$-marked particulate filtering facepiece respirators. Ann. Occup. Hyg. 53, 117-128. https://doi.org/10.1093/annhyg/men086

Rengasamy, S., Eimer, B., Shaffer, R.E. (2010). Simple respiratory protection-evaluation of the filtration performance of cloth masks and common fabric materials against 20-1000 nm size particles. Ann. Occup. Hyg. 54, 789-798. https://doi.org/10.1093/annhyg/meq044

Rengasamy, S., Eimer, B C. (2011). Total inward leakage of nanoparticles through filtering facepiece respirators. Ann. Occup. Hyg. 55, 253-263. https://doi.org/10.1093/annhyg/meq096

Rengasamy, S., Shaffer, R., Williams, B., Smit, S. (2017). A comparison of facemask and respirator filtration test methods. J. Occup. Environ. Hyg. 14, 92-103. https://doi.org/10.1080/15459624. 2016.1225157

Scheltinga, S.A., Templeton, K.E., Beersma, M.F.C., Claas, E.C.J. (2005). Diagnosis of human metapneumovirus and rhinovirus in patients with respiratory tract infections by an internally controlled multiplex real-time RNA PCR. J. Clin. Virol. 33, 306-311. https://doi.org/10.1016/j.j cv.2004.08.021

Serfozo, N., Ondráček, J., Otáhal, P., Lazaridis, M., Ždímal, V. (2017). Manikin-based size-resolved penetrations of CE-marked filtering facepiece respirators. J. Occup. Environ. Hyg. 14, 965-974. https://doi.org/10.1080/15459624.2017.1358816

Tang, J.W., Nicolle, A.D., Klettner, C.A., Pantelic, J., Wang, L., Suhaimi, A.B., Tan, A.Y.L., Ong, G.W.X., Su, R., Sekhar, C., Cheong, D.D.W., Tham, K.W. (2013). Airflow dynamics of human jets: Sneezing and breathing-potential sources of infectious aerosols. PLOS ONE 8, e59970. https://doi.org/10.1371/journal.pone.0059970

Ueki, H., Furusawa, Y., Iwatsuki-Horimoto, K., Imai, M., Kabata, H., Nishimura, H., Kawaoka, Y. (2020). Effectiveness of face masks in preventing airborne transmission of SARS-CoV-2. mSphere 5, e00637-20. https://doi.org/10.1128/mSphere.00637-20

World Health Organization (WHO) (2020). Rational use of personal protective equipment for coronavirus disease (COVID-19) and considerations during severe shortages: Interim guidance, 6 April 2020 (No. WHO/2019-nCov/IPC_PPE_use/2020.3). World Health Organization.

Zhou, S.S., Lukula, S., Chiossone, C., Nims, R.W., Suchmann, D.B., Ijaz, M.K. (2018). Assessment of a respiratory face mask for capturing air pollutants and pathogens including human influenza and rhinoviruses. J. Thorac. Dis. 10, 2059. https://doi.org/10.21037/jtd.2018.03.103

Zhu, N., Zhang, D., Wang, W., Li, X., Yang, B., Song, J., Niu, P. (2020). A novel coronavirus from patients with pneumonia in China, 2019. N. Engl. J. Med. 382, 727-733. https://doi.org/10.105 6/NEJMoa2001017

Zhuang, Z., Bradtmiller, B. (2005). Head-and-face anthropometric survey of US respirator users. J. Occup. Environ. Hyg. 2, 567-576. https://doi.org/10.1080/15459620500324727 